\title{
ART GAMES: MEDIOS DIGITALES ARTÍSTICOS INTERACTIVOS PARA LA EDUCACIÓN
}

\section{Art games: Interactive digital artistic media for education}

\author{
Marqués Ibáñez, Ana ${ }^{1}$ \\ Universidad de La Laguna \\ amarquez@ull.edu.es
}

Material original autorizado para su primera publicación en la revista académica REDMARKA. Revista Digital de Marketing Aplicado.

https://doi.org/10.17979/redma.2017.01.019.4850

Recibido: 24 Mayo 2017

Aceptado: 28 Octubre 2017

\section{Resumen:}

Esta comunicación incide en la utilización de los art games en educación y como propuesta para el desarrollo de la creatividad. En la introducción se conceptualiza sobre la idea de art games dentro del arte y como éstos pueden ser de interés en ámbitos educativos.

Seguidamente se expondrán una serie de videojuegos que tienen relación con este campo artístico.

Sobre la idea de Aprendizaje Basado en el Juego (Game Based Learning) y de estrategias como la Gamificación (Gamification) se definen ambos conceptos, se citan ideas para establecer sus diferencias sobre esta temática en relación a los videojuegos.

Para la propuesta educativa se utilizarán las plataformas Kodu y Scratch para la creación de videojuegos y el estudio o aprendizaje de nuevos sistemas de programación por bloques y cómo se pueden vincular con otras ramas artísticas

${ }^{1}$ Profesora Contratada Doctora en Régimen de Interinidad. Departamento de Bellas Artes. Didáctica de la Expresión Plástica. Facultad de Educación. Universidad de La Laguna. Doctora en Bellas Artes por la Universidad de Granada. 
como: la música, interactividad y nuevos diseños en otras plataformas como dispositivos móviles, ordenadores y consolas. Estudio de las diversas plataformas que proporcionan de forma más amplia y plural el desarrollo de videojuegos artísticos.

Se analizará lo que es el Diseño del videojuego (Game Design) en el que tiene que existir un grupo colaborativo de profesionales tales como diseñador y programador, así como las destrezas que éstos necesitan para el desarrollo y creación de un videojuego que puede ser aplicable para videojuegos artísticos o educativos.

Los objetivos serán los de evaluar que videojuegos son útiles para el ámbito educativo y pueden ser de interés tanto si son de tipo Videojuego Artístico (Game Art) o Videojuegos educativos (Serious Games). El objetivo de la propuesta será experimentar un medio innovador para facilitar la atención, fomentar la psicomotricidad y la creatividad.

Las conclusiones serán un extracto del estudio comparativo entre los diversos videojuegos.

Palabras clave: Videojuegos artísticos, arte hibrido, educación.

\section{Abstract:}

This presentation addresses the use of art games as an educational model and means to develop creativity. We begin by introducing and conceptualising the idea of art games within the field of art, and their potential interest in educational settings.

Next, a series of art-related video games are presented.

After defining the concepts of Game Based Learning and Gamification, we will highlight several ideas that differentiate these two concepts in relation to video games.

In terms of educational application, the Kodu and Scratch platforms will be used to create video games and also to learn about the latest block-based programming systems. In addition, we will explore the connections between video games and other branches of art, such as music, interactivity, and new designs for digital platforms: mobile phones, computers and consoles. This study also explores the use of different digital platforms to provide broader and more diverse possibilities to develop artistic video games. The next section of the presentation discusses the 
concept of Game Design, the collaborative group of professionals involved in this process, such as the designer and programmer, and the skills required to develop and create a video game that can be used as an artistic or educational video game.

The objectives are to assess which video games may be useful for educational purposes, and whether Art Games and Serious Games may be of interest in the field of education. The principal aim of this project is to test the ability of this innovative medium to facilitate attention, promote psychomotor development, and to encourage creativity.

Conclusions will be drawn from the comparative study of several video games.

Keywords: Art games, hybrid art, education.

\section{MARCO TEÓRICO}

Analizaremos lo que es el concepto de Juego, la definición de Game Play y lo que se consideran como un videojuego. Este marco principal se ajusta a una amplia variedad de términos de diferentes épocas ya que la idea de juego y videojuego están muy ligadas y son cada vez más amplias en su categorización.

"Enumeremos de nuevo las que nos parecen características del juego. se trata de una acción que se desarrolla dentro de ciertos límites de tiempo, espacio y sentido, en un orden visible, según reglas libremente aceptadas y fuera de la esfera de la utilidad o de la necesidad materiales." (Huizinga, 1987, p. 157)

La idea de Game Play que se puede aplicar al juego tradición y a los videojuegos se define como:

"Esta forma de juego es una categoría estrecha de la actividad que sólo se aplica a lo que ya se ha definido como "juegos". El Game Play es la interacción de carácter oficial que se produce cuando los jugadores siguen las reglas de un juego y la experiencia de su sistema a través del juego." (Salen y Zimmerman, 2004, p. 303)

Según afirma (Newman, 2004: 11) "para que un videojuego sea exactamente eso es necesario que cumpla una serie de características: que tenga audio y vídeo, interfaz y gameplay". 
El video o el audio se puede encontrar en un video y el interfaz (interface) están situados en internet o en un teléfono móvil, pero la idea de jugabilidad (gameplay) es una característica de los videojuegos y juegos. La jugabilidad se crea a partir de una serie de finalidades y normas; sin estas reglas que pueden ser seguidas o no según dicte la estructura del juego no puede existir un juego.

\subsection{Introducción}

Desde el inicio de los videojuegos en la primera década de los 70 del s. XX hasta la actualidad éstos se han transformado en una industria internacional de gran importancia en sectores como el cultural, tecnológico, económico o social. El videojuego se ha relacionado con otras áreas como la televisión, el cine, la literatura, o el cómic por lo que se incluyen en lo que se denomina como transmedia o en el new media art (arte de los nuevos medios).

\subsubsection{Concepto de Art Game en el arte contemporáneo}

Se define el concepto de Art Game, y se realiza una revisión de las diferentes instituciones asociadas al Art Game y su relación con el arte contemporáneo.

El videojuego artístico consiste en una experiencia para el jugador se involucre de forma integral visual y audiovisualmente o a través de los escenarios en que se presentan. Los videojuegos surgen en ocasiones de creadores con innovadoras narraciones, ausencia de retos, objetivos o finalidades que los hacen únicos, así como de gráficos que en ocasiones se originan mediante una imagen abstracta basada en conceptos de arte contemporáneo hibrido en el que convergen diferentes disciplinas artísticas.

El inicio de los videojuegos artísticos (Art Games) como expone (John Sharp, 2015) proviene del arte conceptual:

"La obra de Saito de la serie de Flujo de Ajedrez era parte del gran cambio que se inició con el arte conceptual y de la primacía de las ideas sobre la forma. A partir de la década de 1960, la comunidad del arte contemporáneo se movió desde la especificidad del medio hacia una concepción multimodal, la concepción fluida de la creación artística que reubica el material y el enfoque conceptual desde la habilidad artesanal y la materialidad hacia la realización conceptual. El arte conceptual abrió la práctica artística para permitir una variedad de enfoques que divergen desde los enfoques tradicionales al medio, la artesanía y su intención. Unos treinta años después de este cambio en los valores artísticos, 
el movimiento de game art comenzó dentro del campo más amplio de media art. El fenómeno game art no es un movimiento en sí, sino más bien un grupo no asociado de los artistas de medios que utilizan los juegos para hacer obras de arte. Al principio, el game art era casi exclusivamente ordenador y basado en pantallas, y con frecuencia se realizaron con instrumentos de juego de fabricación. La primera obra de arte de juego fué Orhan Kipcak y Ars Doom deReini Urban. ..." (Sharp, 2015, p. 21-22)
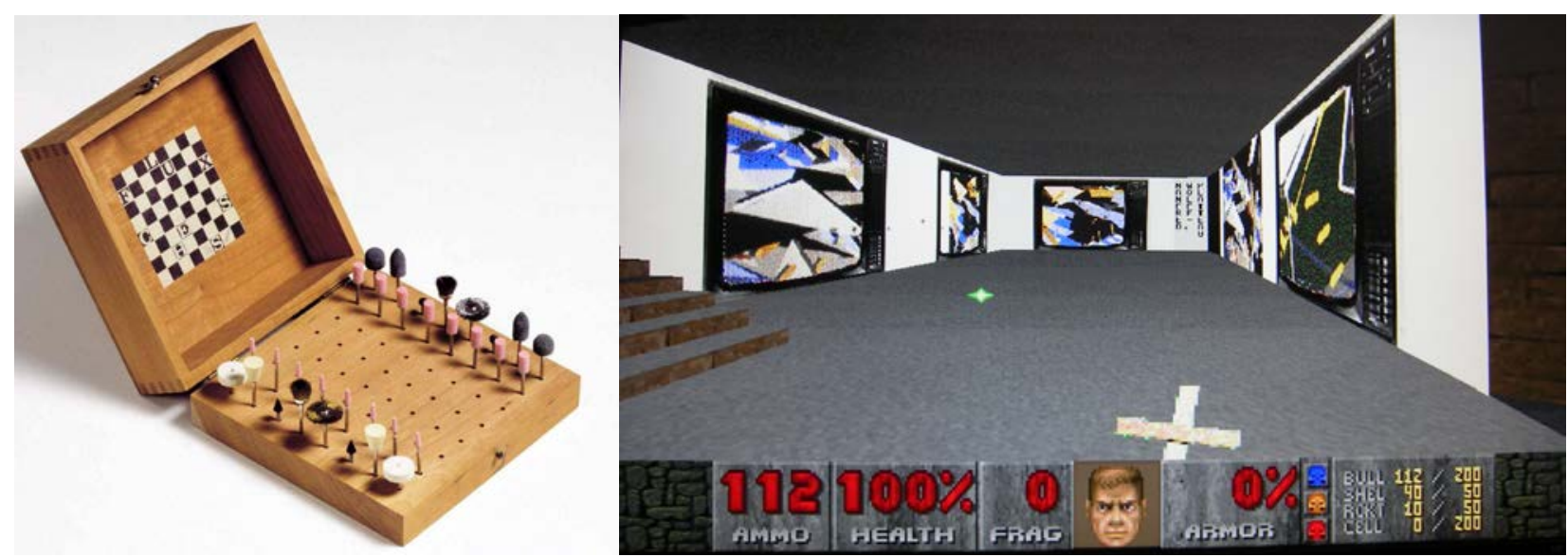

Fig. 1. Flux Chess, 1964. Saito.

Referencia: http://www.fondazionebonotto.org/fluxus/saitotakako/edition/0746e.html

Fig. 2. Ars Doom, Orhan Kipcak and Reini Urban, 1995.

Referencia: http://www.gamescenes.org/2009/11/interview-orphan-kipcak-arsdoom-arsdoom-ii-1995.html

[Consulta: 13/09/2016]

En EEUU es la Academy of Interactive Arts \& Sciences $^{1}$ la que otorga premio a las piezas internacionales de tipo exclusivo para videojuegos ya sean los más populares o de tipo mainstream o las independientes o indies. Esta organización funciona desde 1998 y muestra su apoyo y contribuye al desarrollo de una de las industrias culturales actualmente más influyentes.

En España la institución homologa a la estadounidense es la Academia de las Artes y las Ciencias Interactivas ${ }^{2}$ que es similar a la de EEUU en cuanto a sus finalidades, pero con menor actividad y experiencia en el campo. Existe un nexo de relación entre la Academia de las Artes y las Ciencias Interactivas con la feria más relevante especializada en este tema: Gamelab ${ }^{3}$.

La ruptura con las reglas narrativas establecidas, la reorganización que se presentan en determinados videojuegos, la descomposición e reinterpretación, muestran un caos constructivo que crea piezas asociando diferentes conceptos 
como: la funcionalidad o la simbología. Esta hibridación se transmite a las áreas de conocimiento de los distintos medios artísticos.

Las estructuras hibridas propias de nuestro tiempo corresponden a diferentes campos disciplinarios. De Toro, 2006 afirma que: "la hibridez es una estrategia que se encuentra en diferentes áreas: la epistemológica (en forma de pensamiento), la científica (mediante procedimientos metodológicos), la teórico cultural (en el diseño de espacios transculturales), la urbano-social, la corporal/objetal y, la estrategia transmedial. Ésta última es la hibridez que sucede con el uso de diferentes sistemas, estéticas, géneros, productos, cultura, arte, arquitectura y ciencia. Ésta implica medios de comunicación con sistemas constituidos por signos y mundos virtuales." (De Toro, 2006, p. 1-2)

Los conceptos que definen la historia contemporánea son: Transversalidad, hibridación, multidisciplinaridad, transmedialidad, etc. Es interesante como los museos y diversas instituciones se han interesado por la adquisición de las piezas de Art games entre las más destacadas exposiciones se puede señalar las de Game $\mathrm{On}^{4}$, Talk to $\mathrm{me}^{5}$, Over The Game ${ }^{6}$, The Art of Videogames ${ }^{7}$, Space Invaders ${ }^{8}$, Gamescenes. Art in the Age of Videogames ${ }^{9}$ que es una página web especializada en este tema y por último la doble exposición del centro de Laboral, Centro de Arte y creación industrial en Gijón titulada Playware ${ }^{10}$.

\section{METODOLOGÍA}

La metodología a emplear será a través de la Gamificación o Gamification, conceptos que se describen con posterioridad mediante herramientas como Kodu y Scratch. Plataformas muy visuales que son adecuadas para niveles de primaria 0 infantil.

\subsection{Game based learning versus Gamification}

La definición que Kapp (2012:10) utiliza para describir el termino de Gamification es: Gamification es el uso de la mecánica basada en los juegos, la estética y el pensamiento en juegos para involucrar a la gente, motivar la acción, promover el aprendizaje, y resolver problemas.

Como afirman (Maja Pivec, Anni Koubek, Claudio Dondi, 2004) aunque el concepto de Game based learning ha estado más ligado a educación infantil es fundamental en estadios superiores como el ámbito universitario. 
Game-based learning ha sido en gran medida utilizado en educación de niños pequeños. Mientras que la mayoría de la didáctica de las guarderías se basan en este enfoque, el uso de juegos casi no tiene un papel en la educación superior. A pesar de una amplia aceptación de las teorías constructivistas del aprendizaje, tradicionalmente hemos hecho distinciones definidas entre los juegos y el aprendizaje.

Las universidades son motores para la innovación en nuestra sociedad, y suelen estar abiertos a nuevos conceptos y métodos.

El potencial para el uso de juegos en universidades es especialmente alto; los aspectos interdisciplinares y el pensamiento crítico son elementos que definen el enfoque de juegos ...". (Pivec, Koubek, Dondi, 2004, p. 16)

\section{PROPUESTA EDUCATIVA}

Se utilizarán dos programas básicamente Kodu y Scratch que se describen a continuación:

Kodu se inició en el 2009 para ofrecer la posibilidad a los niños de diseñar juegos a través de Pc y está disponible para su descarga en modo gratuito y para Xbox que también se encuentra disponible en los EEUU mediante un lenguaje de programación muy visual. El programa puede ser utilizado para crear historias conforme a una narración, para propuestas basadas en creatividad, resolución de problemas, así como para el inicio en el aprendizaje de la programación. Su utilización para hacer un juego es sencilla para cualquier usuario, tanto para niños como adultos sin conocimientos previos de diseño o lenguaje de programación.

Con Scratch se pueden programar historias interactivas propias, juegos, y animaciones, y estas creaciones ser compartidas en una comunidad online con otros usuarios.

Scratch es un proyecto del Laboratorio de Medios del MIT del Grupo Lifelong Kindergarten y se puede utilizar a través de su plataforma. Facilita el aprendizaje de pensar creativamente, razonar sistemáticamente y trabajar de forma colaborativa, habilidades que son imprescindibles en la educación actual.

Su diseño está comprendido para niños y adolescentes entre los 8 y 16 años, pero puede ser utilizado en cualquier rango de edad. Scratch está siendo utilizado 
en una gran variedad de entornos diferentes ya sean centros comunitarios, bibliotecas, museos y centros educativos.

La posibilidad de aprender lenguajes de programación es una parte esencial en la sociedad actual. A través del estudio y experimentación con código en Scratch, se desarrollan habilidades específicas como transmisión de ideas o conceptos, creación de proyectos y solución de problemas.

$\mathrm{Kodu}^{11}$ o Scratch ${ }^{12}$ son programas que se utilizan en las aulas debido a su sencillez y manejabilidad pues permiten que el alumnado de infantil o primaria con habilidades tecnológicas muy visuales pueda diseñar su videojuego.

Las elaboraciones de un videojuego son similares a las de cualquier pieza de arte: desde el aumento de la motivación y la autoestima al desarrollo personal, así como la adquisición de competencias específicas.

Se realizó una simulación de la propuesta Educativa en Scratch presionando las flechas del teclado cada personaje cambia de forma y al hacer clic sobre cada uno de ellos emite un sonido propio.

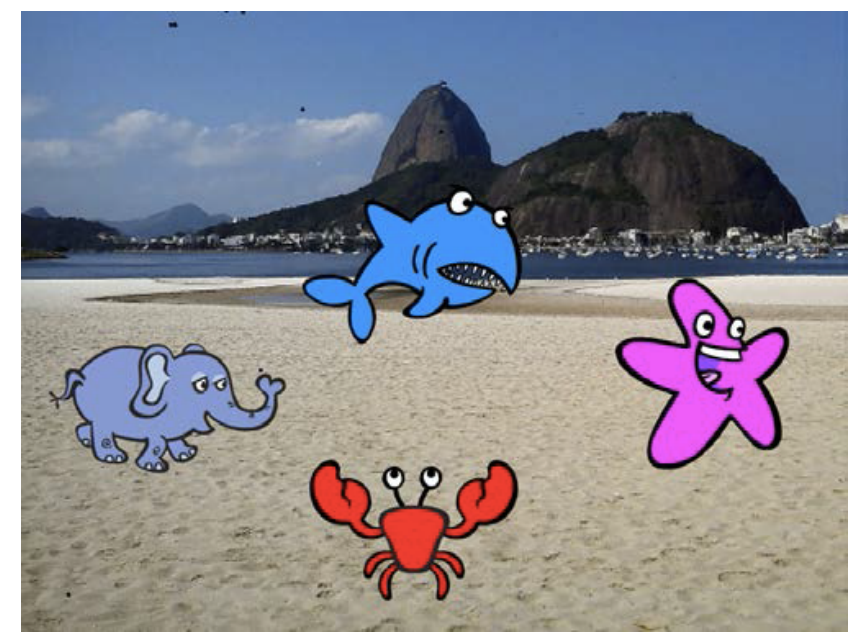

Fig. 3. Escenario Rio de Janeiro, 2016. Manuel García Montosa. Realización en Scratch.

En el diseño de videojuegos la competencia tecnológica y artística no son las únicas que se desarrollan, sino que se pueden incluir temáticas específicas para desarrollar conocimientos teóricos, retos de diseño para ampliar competencias lógico - matemáticas y el fomento del trabajo en grupo. Es conveniente distribuir las tareas para el diseño de un videojuego entre diferentes alumnos en la creación de entornos o espacios, diseño de personajes o la música. 
Ian Bogost muestra el poder que tienen los serious games como movimiento en la industria de los videojuegos.

Entre los programas informáticos, sugiero que los videojuegos tienen un poder de persuasión único. Los recientes movimientos en la industria de los videojuegos, sobre todo el movimiento de serious games, que se discuten a continuación, han tratado de crear videojuegos para apoyar las posiciones sociales y culturales existentes. Pero los videojuegos proporcionan mucho más. Además de transformarse en herramientas de tipo instrumental para los objetivos institucionales, los videojuegos pueden interrumpir y cambiar actitudes y las creencias fundamentales acerca del mundo, lo que lleva a un cambio social significativo a largo plazo. (Bogost, 2007, Prefacio, 9).

\subsection{Análisis de videojuegos artísticos}

El análisis de videojuegos se traza en relación a tres exposiciones realizadas en el LABoral de Gijón en Marzo de 2007, la primera con título de Gameworld: Videojuegos que conectan arte, tecnología y cultura, con una visión narrativa sobre los juegos y el arte en la que se exponían treinta obras contemporáneas que utilizaban los videojuegos como tema principal, tema o como referente. En una segunda planta de la exposición la muestra ofrecía la posibilidad al visitante de jugar con una selección de diez videojuegos históricos de gran difusión diseñados entre 1967 y 1994.

En una tercera exposición Playware se muestran veintitrés obras digitales que pueden ser catalogadas como arte interactivo próximo al videojuego o como game art. El área temática de arte interactivo se estructura en obras de instalación expuestas en festivales, galerías y centros de tecnología y arte.

El modelo de presentación de los videojuegos de Art Games no es a modo de instalación sino que se distribuyen como software para su uso en ordenadores y sistemas de juego específicos, a pesar de que en el ámbito del new media art existen las instalaciones interactivas.

Los juegos que se analizan pertenecen a esta exposición de Playware realizada en la Laboral de Gijón y encontramos dos ámbitos los Art Games y las instalaciones 
artísticas interactivas, en este caso se describirán los videojuegos artísticos que serán los siguientes: Armadillo Run, Elektroplankton, flOw, Golf?, Line Rider, LocoRoco, Mono, Neon, Okami, Rez, Shift, Toribash y Vib-Ribbon. La exposición Playware trata de que Occidente amplié su visión del juego como función del arte digital y del arte como un instrumento del juego.
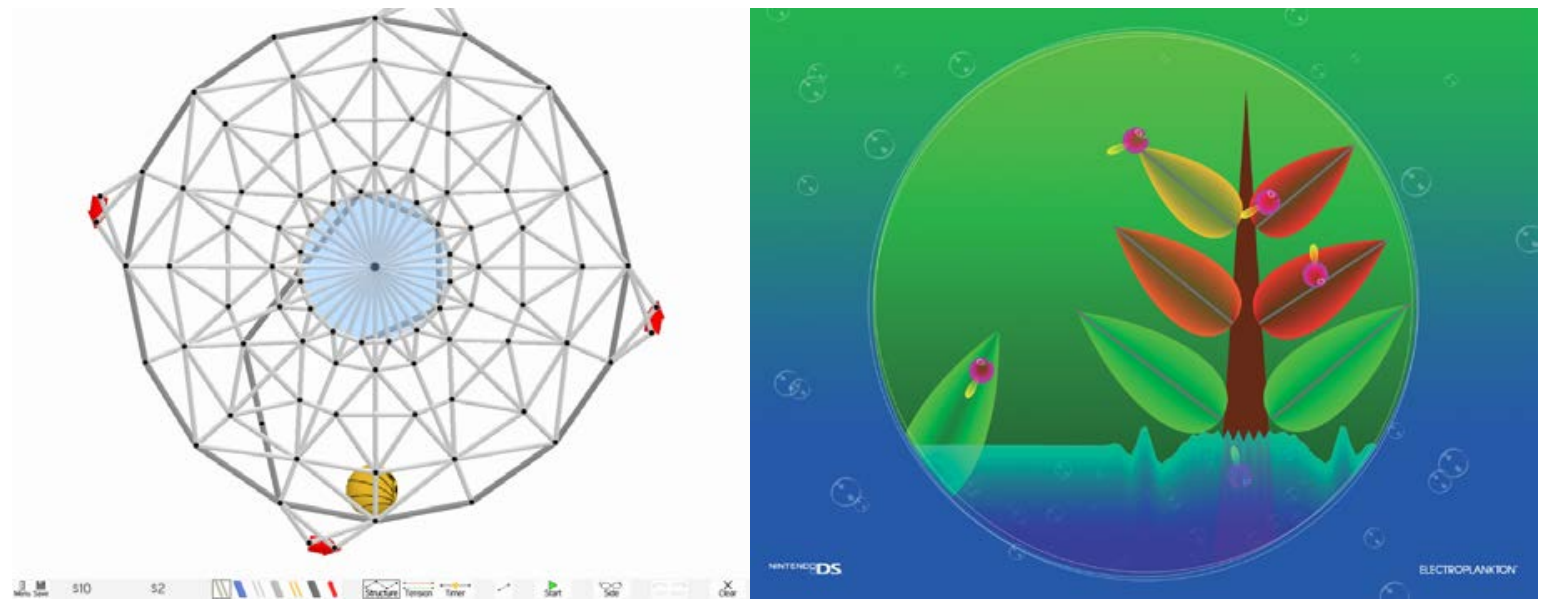

Fig. 4. Armadillo Run, 2006. Peter Stock. Reino Unido. Pc.

Fig. 5. Electroplankton, 2005. Toshio Iwai. Japón. Nintendo DS Hand Held.

Referencia: http://www.laboralcentrodearte.org/es/files/2007/exposiciones/playware-doc/catalogoplayware [Consulta: 01/09/2016]

Armadillo Run se compone de una serie de estructuras en formato de puzzle con movimiento y se basa en fundamentos físicos, el jugador tiene que diseñar estructuras que puedan desplazar a un armadillo en la pantalla. Alcanzar el final de cada nivel depende de una serie de parámetros que son similares a las limitaciones en un contexto real. Hay varias soluciones para cada nivel, por lo que se potencia la creatividad y la capacidad de solucionar problemas. Al finalizar un nivel, se puede volver para mejorar el diseño y tener mejores resultados.

La fuerza del videojuego reside en que los jugadores pueden utilizar el método de ensayo-error en su diseño y mejorar las simulaciones de un objeto físico en determinadas estructuras.

Elektroplankton desarrollado por el artista digital Toshio Iwai, define el proyecto como "juego de arte new media para ser intervenido".

De un diseño gráfico muy cuidado muestra diferentes escenarios con diez tipos de personajes sonoros denominados plankton. Cuando se mueve o selecciona el plankton a través de la pantalla táctil de la Nintendo DS o a través del micrófono, el jugador puede crear, modificar o superponer diferentes melodías musicales en el 
tiempo. La creación musical y visual del videojuego transforma un juego manual de plataforma en un nuevo instrumento musical que crea imágenes y música nuevas. Otra creación de Iwai, es un dispositivo interactivo musical el Tenuri-On de Yamaha que es sensible al tacto.

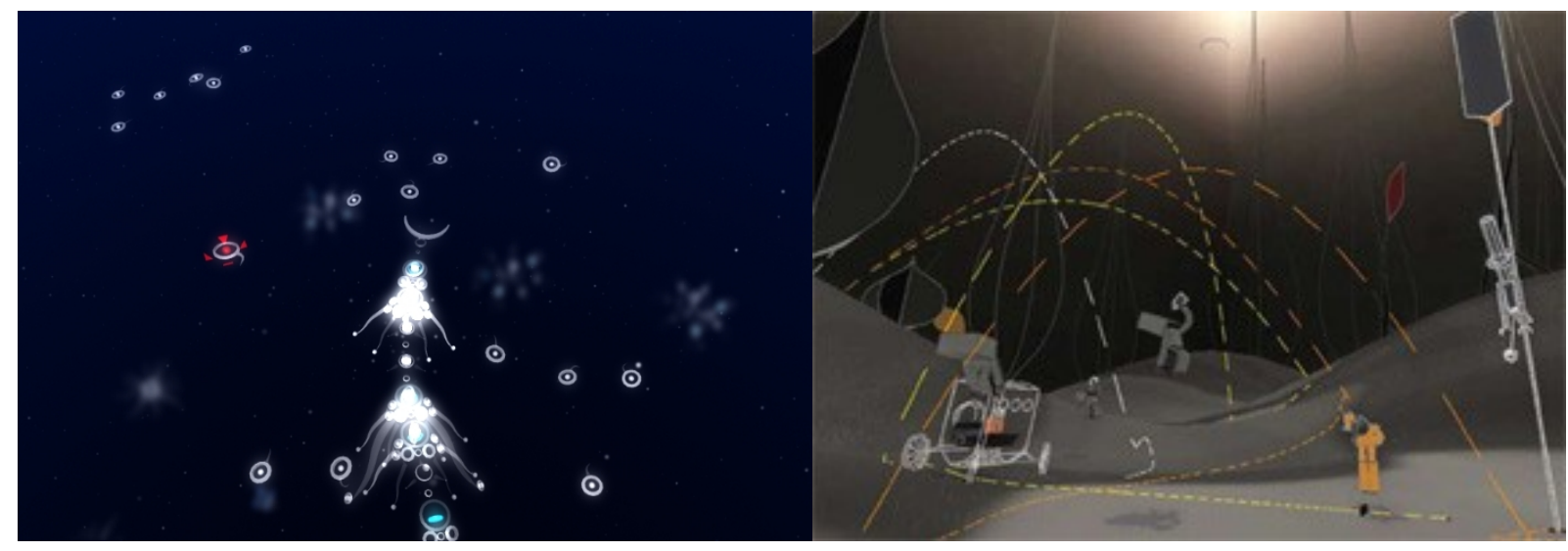

Fig. 6. flOw, 2007. Jenova Chen, Nick Clark y Austin Wintory. EEUU. Thatgamecompany. Sony PlayStation 3.

Fig. 7. Golf?, 2007. Andrew Laing. Detective Brand: Luke Hetherington, Alex Austin. EEUU. Chronic Logic: Josiah Pisciotta. Pc.

Referencia: http://www.laboralcentrodearte.org/es/files/2007/exposiciones/playware-doc/catalogoplayware

[Consulta: 03/09/2016]

flOw se originó sobre la tesis de posgrado de Jenova Chen del Departamento de Medios Interactivos en la Escuela de Artes Visuales de la Universidad del Sur de California. Su autor estudió la teoría de flujo, investigada por el psicólogo Mihaly Csikszentmihalyi que la define como un estado al que una persona puede alcanzar cuando las diferentes destrezas y su desafío se complementan, lo que proporciona un sentido de atemporalidad y una capacidad para realizar actividades a un nivel mayor. flOw trata de fomentar ese estado, muestra tranquilidad fomentando así que el nivel de dificultad se adapte de forma automática con el juego. En su inicio fue diseñado en Adobe Flash, pero posteriormente se realizó una versión que se podía descargar encargo de Sony Computer Entertainment destinado a PlayStation 3.

Golf? es similar al diseño visual de los primeros juegos de deportes, con gráficos de carácter minimalista en $3 d$ inciden en la idea de la física básica en la que se fundamenta el deporte. El videojuego es una contraposición a los videojuegos en $3 d$ hiperrealistas actuales y es sólo en juegos que muestran la acción en dos dimensiones donde se puede encontrar ese carácter minimalista. Se puede jugar en 
modo multijugador en tiempo real mediante conexiones LAN o IP, un concepto diferente de juego que no se estructura mediante el patrón de uno contra uno. El juego muestra curiosidades como un caddy robot volador al que le gusta el alcohol o un carro de golf movido por un cohete.

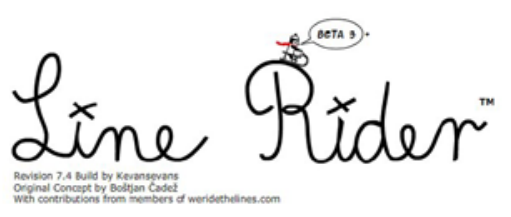

$$
\text { New Track }
$$

Load Track

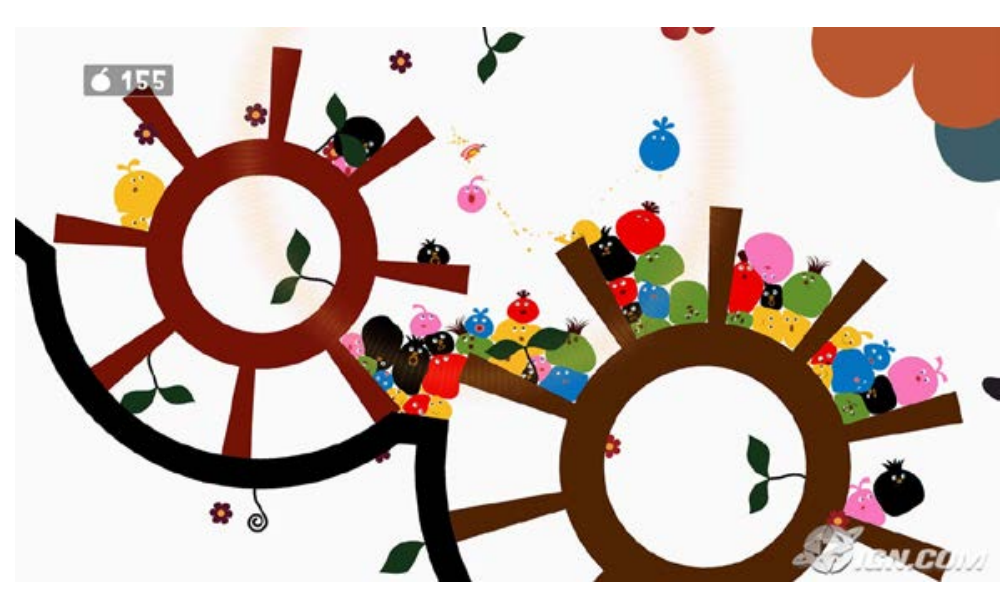

Fig. 8. Line Rider, 2006. Boštjan Cadež. Publicado por inXile entertainment. Eslovenia. Pc. Referencia:

http://www.laboralcentrodearte.org/es/files/2007/exposiciones/pl

\section{ayware-doc/catalogo-playware}

Fig. 9. LocoRoco, 2006. Tsutomu Kouno. Japón. Sony PSP.

Referencia: http://www.loco-roco.net/?go=Irc loesung 2

[Consulta: 06/09/2016]

En Line Rider los usuarios diseñan con el ratón líneas sobre las que se mueve un hombre sobre un trineo. Se incorporan simulaciones físicas y el trazado debe tener unas condiciones de diseño para que el personaje no se caiga del trineo. El juego no presenta un objetivo específico ni puntos para alcanzar, por lo que su creador lo describe como un juguete no un juego. El espacio del juego es una superficie blanca como un Etch-A-Sketch con muchas posibilidades que dependen 
de la imaginación y creatividad del usuario. Los jugadores utilizan las herramientas de dibujo para crear paisajes de apariencia en tres dimensiones que conformas narraciones de tipo visual y espacial. Fue pensado como un proyecto para una clase de ilustración, pero ha tenido mucho éxito.

LocoRoco es un juego con unos gráficos impactantes y una forma de jugar innovadora. El jugador se mueve por mundos modificando el paisaje sin desplazar a sus personajes los Loro Rocos, con movimientos simples que se pueden inclinar, girar y saltar en paisajes bidimensionales, recolectando flores y creciendo en el

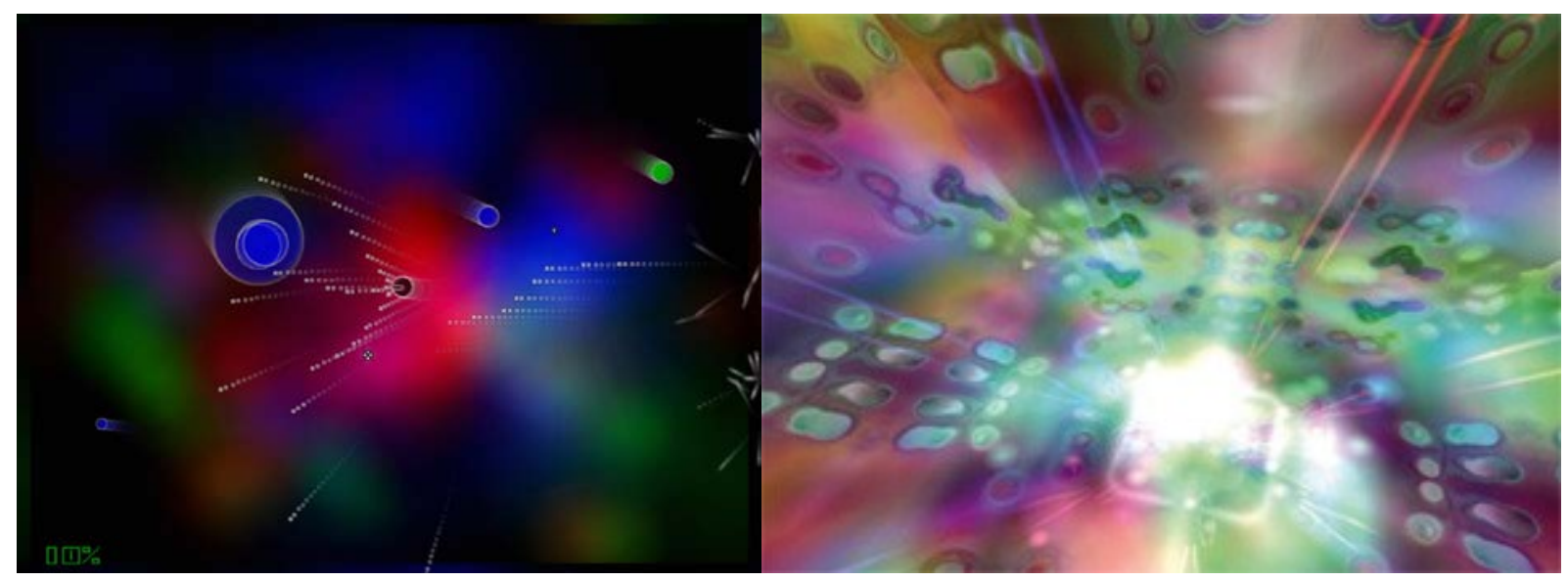

Fig. 10. Mono, 2007. Chris Jeffels, Lauri Suoperä, Aaron Frensley, Michael R. King, Mobeen Fikree. Binary Zoo. EEUU. Pc.

Fig. 11. Neon, 2006. Jeff Minter. Llamasoft. Reino Unido. Software para la consola Microsoft 360. Referencia: http://www.laboralcentrodearte.org/es/files/2007/exposiciones/playware-doc/catalogoplayware [Consulta: 05/09/2016]

proceso. Su diseño es un ejemplo de juego artístico que transforma la música y las imágenes abstractas en una parte integral de la experiencia. El color y los personajes que cantan muestran un juego ameno, lúdico y accesible para niños y adultos.

Mono es un juego de disparar (shooter) que fue creado como un test para juegos como Binary Zoo y es el color el que lo convierte en una experiencia fascinante. La finalidad es poder pasar la pantalla de negro a blanco con el disparo de formas circulares que se encuentran en el espacio y depositan manchas de color una vez destruidas.

Mono representa las características del género de lucha espacial y se pueden señalar videojuegos como Galaga (1982) y Tempest (1981), que se caracterizan por la unión entre el reto de jugar y las formas visuales de imágenes en movimiento. 
Actualmente este género está vigente en juegos para ordenador y para consola como Geometry War (Bizarre Creation, 2006), el premiado juego indie Everyday Shooter (Queasy Games, 2007) y Space Giraffe, en homenaje al videojuego Tempest diseñado por Jeff Minter y Llamasoft.

Neon surge de la creación de Jeff Minter y Llamasoft, que es un software de visualización de audio interactivo que se incluye en las unidades de la Xbox 360.

Jeff Minter es conocido por sus juegos de carácter psicodélico del tipo disparador en espacios y sus sintetizadores de luz. Una de las características de la música realizada por ordenador y de los software de reproducción tales como iTunes y Windows Media Player es la visualización del audio. Los datos que se obtienen del audio como: ritmo, tono, volumen y densidad se utilizan para crear animaciones abstractas en tiempo real.

Neón es diferente a otros visualizadores, es un instrumento performativo.

Debido a que forma parte de televisiones de alta definición, los sintetizadores de imágenes que se mueven ccon la música que se selecciona.
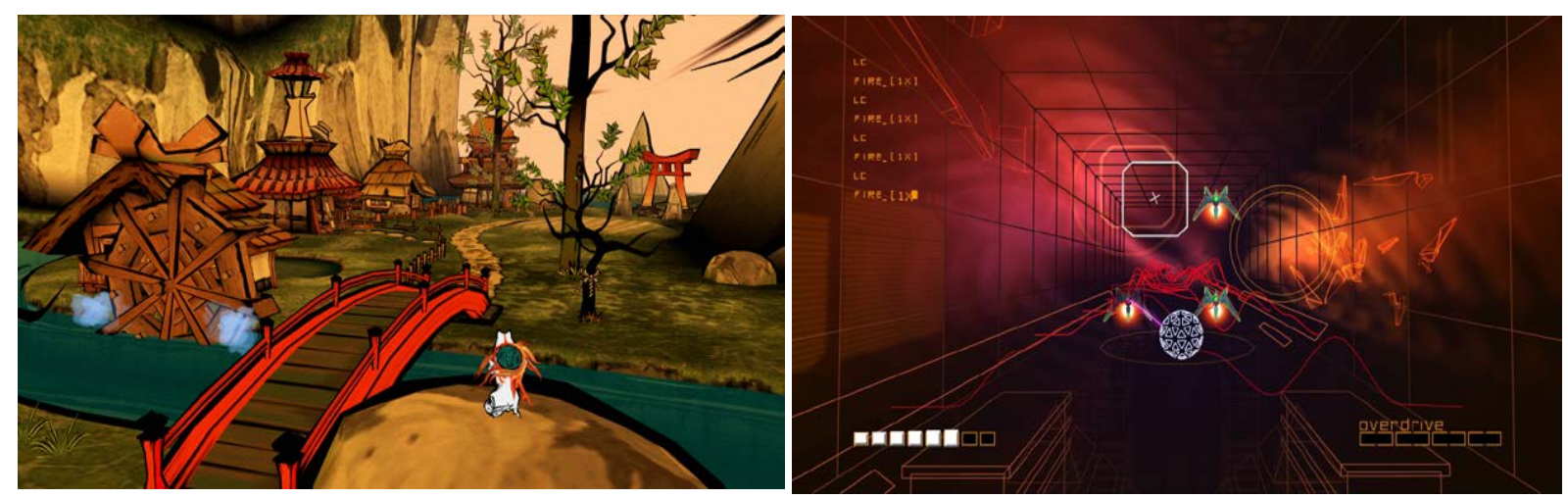

Fig. 12. Okami, 2006. Hideki Kamiya. Clover Studio. Japón. Sony PlayStation 2. Referencia: http://www.laps4.com/avances/427026-

juegos playstation parecidos the legend of zelda.html

Fig. 13. Rez, 2002. Tetsuya Mizuguchi. United Game Artists, Sonic Team. Japón. Sony PlayStation 2. Referencia: http://www.laboralcentrodearte.org/es/files/2007/exposiciones/play ware-doc/catalogo-playware [Consulta: 08/09/2016] 
Okami utiliza la temática de un mito japonés, la protagonista es Amaterasu, una diosa del sol con forma de lobo blanco que trata de dar vida a un paisaje desolado. Se basa en el videojuego de aventuras La Leyenda de Zelda, en el que se incorporan las luchas como pruebas de ingenio proporcionando una excelente narrativa.

Su característica son los dibujos que recuerdan a las acuarelas japonesas de sumi-e y los grabados de Hokusai. La animación que emplea es la "cel-shaded", técnica no-fotorealista de ilustración creada para realizar gráficos que sean parecidos a los dibujos, ya sean caricaturas artesanales o en pinceladas de tipo japonés.

El estilo pictórico es parte fundamental de los aspectos visuales y de su acción. Las pruebas que deben atravesar Amaterasu hacen que sea imprescindible el uso del "Pincel Celestial", cuando se debe pintar un puente para que pueda cruzar un rio o para abrir un espacio en el cielo para dejar pasar la luz. Los puzzles que aparecen en el juego retan al participantes en sus habilidades con el dibujo y los usos que se le puede dar al pincel se amplían cuando el juego avanza.

Rez se basa en las teorías de Kandinsky sobre las asociaciones de la sinestesia que se produce entre colores y sonidos. El juego muestra una experiencia multisensorial en un juego de disparo espacial ("space shooter"), y sucede en una sofisticada red informática no en un espacio.

Cuando el usuario dispara a los virus informáticos, se crean ritmos y música que constituyen parte del videojuego, además las experiencias táctiles se emiten mediante los controladores de la PlayStation y en su versión nipona mediante un accesorio llamado "trance vibrator".

Rez transforma los habituales visualizadores musicales de carácter psicodélico a una experiencia multisensorial. Mientras las extensiones táctiles y de sonido fomentan la experiencia del jugador, los gráficos wireframe simplifican la percepción visual. 

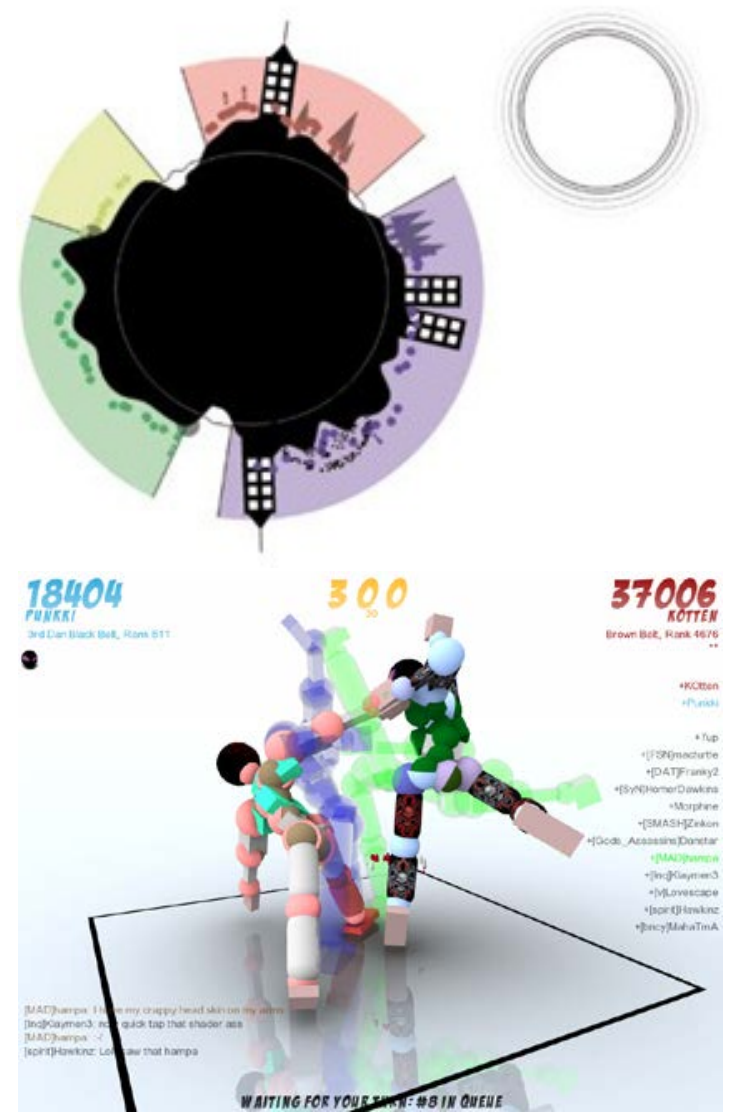

Fig. 14. Shift, 2007. Max McGuire. EEUU. Pc. Referencia:

Fig. 15. Toribash, 2007. Hampus Söderström. Suecia. Pc. Referencia: http://www.laboralcentrodearte.org/es/files/2007/exposiciones/playware-doc/catalogoplayware [Consulta: 11/09/2016]

Shift fue creado a través de la participación en un concurso de diseño en la Boston Game Jam del 2007. El videojuego anima al jugador a que participe en el paisaje, cambie las relaciones sociales y trata de concienciar sobre la problemática global.

El jugador debe ofrecer suministros de metal y madera para que determinados grupos avancen hacia la era espacial. El juego se fundamenta en principios de teoría geopolítica y antropología social que influyen en la dinámica de los grupos y su desarrollo.

El autor de Persuasive Games: The Expressive Power of Videogames afirma:

"Los videojuegos son generalmente un subgénero de los medios computacionales que expresa más que otros tipos, por ejemplo, software de productividad. Con el término expresivo me refiero a que las metas de 
representación de los videojuegos son similares a la literatura, el arte y el cine, en contraposición a objetivos instrumentales similares a utilidades y herramientas." (Bogost, 2007, p. 45).

Toribash es un juego de lucha al estilo tradicional pero basado en la estrategia. A través del tiempo detenido, los jugadores manipulan las extremidades de un personaje articulado que es un luchador y progresa continuamente. El jugador se debe anticipar a los desplazamientos de su oponente para atacar y defender sin caer y con ello ser descalificados.

Es un juego de creación independiente y utiliza la estrategia y la creatividad. Es de estética minimalista y en la utilización del tiempo se asemeja a las complicadas coreografías de combate en The Matrix y a películas de artes marciales.

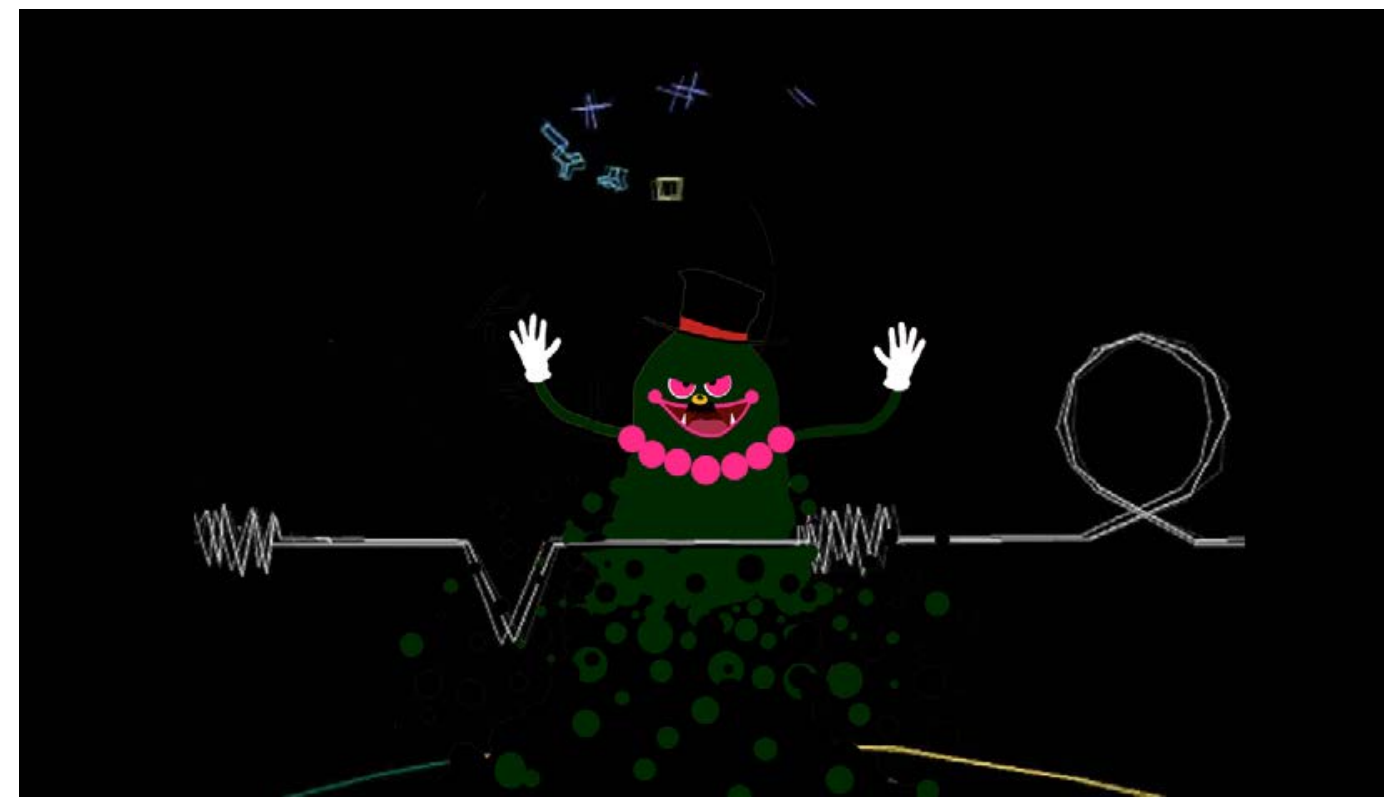

Fig. 16. Vib-Ribbon, 1999. Masaya Matsuura, NanaOn-Sha. Japón. Sony PlayStation. Referencia: http://www.laboralcentrodearte.org/es/files/2007/exposiciones/playwaredoc/catalogo-playware [Consulta: 11/09/2016]

Vib-Ribbon con estética de dibujo bidimensional en blanco y negro, da importancia a la música y las acciones. El videojuego da la posibilidad a los jugadores de insertar CDs en el juego, ejecutando el programa que se encuentra en la memoria de la consola, esto posibilita crear nuevos niveles a través de la música que selecciona el usuario, desde el Smooth Jazz hasta la música house. 


\section{GAME DESIGN}

El Diseño de un videojuego y los elementos que lo constituyen se pueden basar en cuatro elementos básicos: Mecánica, historia, estética y tecnología.

Mecánica: Se refiere a las reglas y métodos en los que se fundamenta el videojuego. En ésta se describe la finalidad del juego, como lograr los objetivos y lo que ocurre cuando logran sus metas.

Historia: Son la serie de acontecimientos que se desarrollan en el videojuego, puede ser lineal y planificado, o de ramificación y emergente.

Estética: Es el modo en el que se ve el juego, cómo se puede percibir su sonido y la experiencia que el jugador puede tener de forma integral. La estética es una parte muy importante del Diseño del juego, ya que define una experiencia directa con el jugador.

Tecnología: No solo nos referimos a alta tecnología sino a los materiales e interacciones que hacen que un juego funcione. La tecnología permite realizar determinadas acciones y le imposibilita efectuar otras, es un medio que permite una creación estética, en la que se produce la mecánica y a través de la que se puede desarrollar una historia.

En el proceso de diseño de un videojuego es interesante valorar el concepto de juego significativo, (Katie Salen y Eric Zimmerman, 2004) lo definen como:

El juego significativo en un juego surge de la relación entre la acción del jugador y el resultado del sistema; es el proceso por el que un jugador toma acción en el sistema diseñado de un juego y este sistema responde a la acción. El significado de una acción en un juego se establece en la relación entre resultado y acción. (Salen y Zimmerman, 2004, p. 34)

\section{OBJETIVOS}

Se evalúan que tipo de videojuegos entre los expuestos son útiles para el ámbito educativo tales como: Armadillo Run, Electroplackton, Loco Roco, Okami y Rez.

Armadillo Run: Es un videojuego en el que se puede estudiar la sensación de movimiento, así como los fundamentos físicos que se establecen en los distintos niveles del juego.

Elecktropackton: Es útil para el estímulo y el desarrollo de la creatividad mediante el estudio de su cuidado diseño, su análisis del color y la experimentación con piezas sonoras específicas. 
Loco Roco: Se puede emplear para el análisis de personajes de forma simple y los escenarios para la posterior creación de un videojuego, el estudio del color y la creatividad en ámbitos como el dibujo o la ilustración.

Okami: Diseño de un videojuego en el que se destaca la utilización de herramientas propias del dibujo y la pintura y puede servir para el desarrollo de nuevos escenarios, así como de nuevos tipos de herramientas para utilizar en el dibujo y la pintura como el sumi-e o el análisis de los grabados de Hokusai.

Rez: La construcción del videojuego que se plantea mediante un espacio tridimensional puede servir para el desarrollo de la visión espacial, mejora de la atención, la visión y la cognición.

Por un lado la propuesta educativa propone la utilización de Scratch y Kodu y por otra mediante el visionado de éstos últimos videojuegos que se evalúan y se establecen mediante una tabla cuales pueden ser útiles para el arte y la educación en otras áreas curriculares.

\section{FINALIDAD}

Tras el visionado de los diferentes videojuegos artísticos expuestos y ofrecer la posibilidad de jugar a ellos para poder potenciar la creatividad y abrir nuevos horizontes de creación y diseño en el arte contemporáneo.

Se realizarán sesiones prácticas para que el alumnado aprenda el manejo y uso de herramientas muy visuales como Kodu y Scratch. Con éstas el estudiante podrá aprender lenguaje de programación mediante bloques, el desarrollo de personajes, escenario y narrativa.

\section{RESULTADOS}

Los videojuegos son una industria emergente que está cambiando las instituciones educativas y el modo en el que se puede desarrollar el aprendizaje y transmitir los conocimientos teóricos y prácticos.

Los centros educativos han encontrado un nuevo método alternativo a través del juego para que los estudiantes desarrollen habilidades flexibles y adaptadas que les posibilita aprender mediante los videojuegos. Se ha desarrollado en áreas como la Literatura, Ciencia, Geografía, Lógica, Historia, Matemáticas, la creatividad y la comunicación.

A través de los videojuegos se desarrollan habilidades como: destrezas para resolver problemas y fomentar la negociación entre pares, desarrollo del juicio 
crítico, el análisis y el pensamiento estratégico, fomento de las habilidades de comunicación y trabajo en red, creación de nuevas habilidades narrativas y navegación transmedia, posibilitar la construcción de patrones de pensamiento no lineales, construyendo actividades más flexibles y abiertas.

Como resultados se realizará la creación de un videojuego de cuidado diseño en el que se valoren los aspectos estéticos en el escenario, creación de personajes y objetivos propuestos, así como finalidades conseguidas con el videojuego.

\section{DISCUSIÓN Y CONCLUSIONES}

Como conclusión los videojuegos han aportado y perfeccionado muchas habilidades al campo artístico y educativo.

Habilidades tan importantes como de lectura, escritura y lenguaje, desarrollo de personajes, aprendizaje independiente, coordinación mano-ojo, habilidad para la multitarea, educación financiera, práctica reflexiva, habilidades matemáticas, creatividad, de movimiento, nociones en física y trabajo en equipo.

\section{REFERENCIAS BIBLIOGRÁFICAS}

AAVV. (2014). Videojuegos y Ludificacion de los aprendizajes. Revista: Aprender a educar con tecnologia. Instituto Nacional del Proferorado Técnico. Universidad Tecnológica Nacional (UTN). N 9. Octubre, 2014. Recuperado el 20 de Julio de 2016, de: http://inspt.utn.edu.ar/revista/anterior 01.html

AAVV. (2008). Gameworld Expansion Pack: Playware* El mundo de los videojuegos: Pack de Expansión. Gijón: LABoral Centro de Arte y Creación Industrial.

Ballarin Baigorri, L. (2006) Game Art. Nuevos entornos creativos para el arte y el juego. Revista: Temps d'Art Monográfico Reload. Interferencias entre el arte y los videojuegos. Número: 28 Pág. 20 - 23. Valencia.

Ballarin Baigorri, L. (2005) Game as Critic as Art 2.0. Revista: Joystick Publicación online. Recuperado el 25 de Julio de 2016, de: $\underline{\text { http://www.jstk.org/txt/gamecritic.html }}$ 
Bernat, A. Catalá, A. Feixa, C. Grupo F9, Jaén, J. Lacasa, P. Martínez, R. Méndez, L. Mocholí, J. A. y Moreno, I. (2008). Videojuegos y aprendizaje. Barcelona: Editorial GRAÓ.

Bogost, I. (2007) Persuasive Games: The expressive power of videogames. Cambridge, Massachusetts: The MIT Press.

Canet, M. (2012) Innovación en interfaces para videojuegos desde el Game Art. Revista: Revista de Estudios de Juventud. Videojuegos y juventud. Septiembre. No 98 . Recuperado el 22 de Julio de 2016, de: http://www.injuve.es/sites/default/files/2012/50/publicaciones/Revista98 co mpleta.pdf

De Toro, A. Figuras de la hibridez. Transculturación. Recuperado el 8 de Septiembre de 2016, de: http://home.uni-leipzig.de/detoro/wpcontent/uploads/2006/02/2006-Hibridez Ortiz Retamar-Artikel.pdf

Gray D., Brown, S., Macanufo, J. (2012). Gamestorming: 83 juegos para innovadores, inconformistas y generadores del cambio. Madrid: Deusto.

Guarinos, V. (2007). Transmedialidad: el signo de nuestro tiempo. Recuperado el 1 de Septiembre de 2016, de: http://www.revistacomunicacion.org/pdf/n5/articulos/transmedialidades el signo de nuestro tiempo.pdf

Huizinga, J. (1987). Homo Ludens. Madrid: Alianza Editorial.

Kapp, K M. (2012). The Gamification of Learning and Instruction: Game-based Methods and Strategies for Training and Education. San Francisco: Pfeiffer.

Katter, E. (1988). Art Education Journal. Swam intelligence collaboration. An Approach to Art Games. Playing and Planning. May Volumen 41.1998. Issue: 3.

Luján, M. y Cabañes, E. (2014). Hibridaciones contemporáneas: el nuevo ambiente estético. N. ${ }^{\circ}$ 1. Bit y aparte. Arsgames.

Newman, J. (2004). Videogames. London: Ed. Routledge.

Parkin, S. (2014). An Illustrated History of 151 Video Games. A detailed guide to the most important games. Leicester: Lorenz Books.

Pivec, M. Koubek, A. Dondi, C. (2004). Guidelines for Game-Based Learning. Berlin: Pabst Science Publishers.

Revuelta, F. I., Fernández, M. R., Pedrera, M. I. y Valverde, J (Coords.) Actas del II 
Congreso Internacional de videojuegos y educación. CÁCERES, 1-3 Octubre 2013. Recuperado el 2 de Julio de 2016, de: http://cive13.blogspot.com.es/p/actas.html

Revuelta, F. y Guerra, J. (2012). ¿Qué aprendo con videojuegos? Una perspectiva de meta-aprendizaje del videojugador. RED. Revista de Educación a Distancia. No33. 15 de Octubre de 2012.

Sainsbury, M. (2015). Game Art. Art from 40 Videogames and Interviews with their creators. San Francisco: No Starch Press.

Salen, K. y Zimmerman, E. (2004). Rules of Play. Game Design Fundamentals. Massachusetts: The MIT Press.

Sánchez Coteron, L. (2012). Arte y Videojuegos. Mecánicas, estéticas y diseño de juegos en prácticas de creación contemporánea. Tesis doctoral. Madrid: Universidad Complutense.

Schell, J. (2008). The Art of Game Design. A Book of Lenses. Burlington: Morgan Kaufmann Publishers.

Scolari, C. (2013). Homo videoludens 2.0. De Pacman a la gamificación. Transmedia XXI, Laboratori de mitjans interactius. Barcelona: Universitat de Barcelona.

Sharp, J. (2015). Works of Game: On the Aesthetics of Games and Art. Cambridge: Mit Press.

Timón, J. y Vargas, A. (2014). Game-Art: Considerações Sobre a Presença de Grafitti em Games Digitais. DAPesquisa, v.9, n.12, p 01-17, diciembre 2014.

Ware, C. (2008). Visual Thinking: for Design. Burlington: Morgan Kaufmann.

\section{NOTAS}

${ }^{1}$ Academy of Interactive Arts \& Sciences. Recuperado el 9 de Septiembre de 2016, de: http://www.interactive.org/

${ }^{2}$ Academia de las Artes y las Ciencias Interactivas. Recuperado el 9 de Septiembre de 2016, de: http://www.interactivas.org/

3 Gamelab. Recuperado el 9 de Septiembre de 2016, de: http://www.gamelab.es/welcome/

${ }^{4}$ Game On Exhibition. Recuperado el 11 de Septiembre de 2016, de: https://www.barbican.org.uk/bie/game-on 
5 Talk to me Exhibition. Recuperado el 11 de Septiembre de 2016, de: http://www.moma.org/interactives/exhibitions/2011/talktome/

6 Over the Game. Recuperado el 11 de Septiembre de 2016, de: http://www.zemos98.org/overthegame/

7 The Art of Videogames. Recuperado el 11 de Septiembre de 2016, de: http://americanart.si.edu/exhibitions/archive/2012/games/

8 Space Invaders Exhibition. Recuperado el 11 de Septiembre de 2016, de: http://www.space-invaders.com/post/exhibitions/

${ }^{9}$ Gamescenes. Art in the Age of Videogames. Recuperado el 11 de Septiembre de 2016, de: http://www.gamescenes.org/

10 Playware. Recuperado el 11 de Septiembre de 2016, de: http://www.laboralcentrodearte.org/es/exposiciones/playware/

11 Kodu. Recuperado el 11 de Septiembre de 2016, de: http://www.kodugamelab.com/

${ }^{12}$ Scratch. Recuperado el 11 de Septiembre de 2016, de: https://scratch.mit.edu/ 